\title{
Sex Differences in Synaptic Plasticity: Hormones and Beyond
}

\author{
Molly M. Hyer, Linda L. Phillips and Gretchen N. Neigh* \\ Department of Anatomy and Neurobiology, Virginia Commonwealth University, Richmond, VA, United States
}

Notable sex-differences exist between neural structures that regulate sexually dimorphic behaviors such as reproduction and parenting. While anatomical differences have been well-characterized, advancements in neuroimaging and pharmacology techniques have allowed researchers to identify differences between males and females down to the level of the synapse. Disparate mechanisms at the synaptic level contribute to sex-specific neuroplasticity that is reflected in sex-dependent behaviors. Many of these synaptic differences are driven by the endocrine system and its impact on molecular signaling and physiology. While sex-dependent modifications exist at baseline, further differences emerge in response to stimuli such as stressors. While some of these mechanisms are unifying between sexes, they often have directly opposing consequences in males and females. This variability is tied to gonadal steroids and their interactions with intra- and extra-cellular signaling mechanisms. This review article focuses on the various mechanisms by which sex can alter synaptic plasticity, both directly and indirectly, through steroid hormones such as estrogen and testosterone. That sex can drive neuroplasticity throughout the brain, highlights the importance of understanding sex-dependent neural mechanisms of the changing brain to enhance interpretation of

OPEN ACCESS

Edited by: Jordan Marrocco, Rockefeller University, United States

Reviewed by: Brian R. Christie, University of Victoria, Canada

Rebecca M. Shansky, Independent Researcher, Boston, MA, United States

*Correspondence: Gretchen N. Neigh gretchen.mccandless@vcuhealth.org

Received: 26 April 2018 Accepted: 13 July 2018 Published: 31 July 2018

Citation: Hyer MM, Phillips LL and Neigh GN (2018) Sex Differences in Synaptic Plasticity: Hormones and Beyond. Front. Mol. Neurosci. 11:266. doi: 10.3389/fnmol.2018.00266 results regarding males and females. As mood and stress responsivity are characterized by significant sex-differences, understanding the molecular mechanisms that may be altering structure and function can improve our understanding of these behavioral and mental characteristics.

\section{Keywords: sex differences, synaptic plasticity, hormones, mood disorders, stress response}

\section{INTRODUCTION}

Sex differences in behavior can be observed through both scientific inquiry and casual observations in social settings. Although gender roles have been proposed to account for some of the variability in behavior observed between males and females (Ruble et al., 1993; Aggen et al., 2011), behavioral differences extend beyond socially defined roles to physiological differences and certain well-established sexually dimorphic neural structures. Sex differences in neural structures have been documented in humans (Swaab and Fliers, 1985; Allen et al., 1989; Ruigrok et al., 2014; Catenaccio et al., 2016), but also in animals that do not have the social constructs of humans that define genders, including rodents (Gorski et al., 1978; Campi et al., 2013) and avian species (Nottebohm and Arnold, 1976; Balthazart et al., 2009). Some of the most notable sex differences in neural structure are evident in the hypothalamus of the mammalian brain (Gorski et al., 1978) and the song region in the avian brain (Nottebohm and Arnold, 1976). As these brain regions drive sex-specific reproductive-related behaviors, these findings are somewhat unsurprising. 
However, sex differences in neural structures extend beyond brain regions directly involved in reproduction and include structures linked to stress responsivity (for review see McEwen, 2010; Bekhbat and Neigh, 2018) and mood (for review see Bangasser and Valentino, 2014; Gobinath et al., 2015). Over the last three decades, technology and experimental design have advanced the wealth of knowledge regarding sex differences in the brain. Improved imaging techniques along with the elegant use of cell culture and pharmaceutical treatments, have further elucidated sex differences in structure (Phan et al., 2012; Farrell et al., 2015), connectivity (Ingalhalikar et al., 2014), signaling (Skucas et al., 2013; Harte-Hargrove et al., 2015), responsivity (Garrett and Wellman, 2009), and plasticity (Gould et al., 1990; Parducz et al., 2006). Sex differences are evident in adult neurogenesis, the birth of new neurons in adulthood (Ormerod et al., 2004; Tanapat et al., 2005; Mak and Weiss, 2010; Hyer et al., 2017). However, while sex-dependent modifications in adult neurogenesis can have a significant impact on synaptic plasticity (Galea et al., 2006; Livneh and Mizrahi, 2012; Vivar et al., 2016), that discussion is beyond the scope of this mini-review (see: Kempermann et al., 2015). Although these potential mechanisms are important to the understanding of sex differences in neural function, this mini-review focuses specifically on mammalian sex-differences in synaptic plasticity that may contribute to sex differences in neural function.

\section{SEX DIFFERENCES IN STRUCTURAL PLASTICITY}

Spine density, sites for synaptic connections (Holtmaat and Svoboda, 2009), and dendritic arborization reflect changes in existing cell structure that can alter neural function and behavioral outcomes. Chronic stress results in differential patterns of dendritic remodeling in the hippocampus (Galea et al., 1997), prefrontal cortex (PFC; Garrett and Wellman, 2009; Farrell et al., 2015) and basolateral amygdala (BLA, Vyas et al., 2002). Clinical neuropsychiatric disorders related to stress exposure, for instance depression (reviewed in Qiao et al., 2016) and anxiety (reviewed in Leuner and Shors, 2013), occur concomitantly with changes in dendritic structure. The prevalence and incidence of depression and anxiety differ between the sexes (Piccinelli and Wilkinson, 2000; Naninck et al., 2011) and may be, in part, driven by sex-dependent dendritic and synaptic plasticity. Sex-differences have been noted in multiple dimensions of neuronal plasticity including neuron structure, dendritic arborization and spine density (Garrett and Wellman, 2009; Farrell et al., 2015) and sex steroids are sufficient to alter many of these parameters (Figure 1).

\section{Females}

The influence of sex steroids on structural plasticity appears to be more pronounced in females, likely due to cyclical fluctuations in sex steroids. Concentrations of estrogens and progesterone fluctuate across the estrous cycle with peak levels appearing during proestrus and lower levels evident during estrus, metestrus and diestrus (Butcher et al., 1974). The human menstrual cycle shows fluctuations in ovarian steroids as well, with estrogen being lowest early on, then peaking at the end of the follicular phase to initiate ovulation. This peak is followed by a gradual surge in progesterone and a slight rise in estrogen throughout the luteal phase before both drop at the end of the cycle (Protopopescu et al., 2008; Catenaccio et al., 2016). Alterations in spine density are evident in response to changes in ovarian steroid levels across the estrous cycle in female rats. Spine density in area CA1 of the hippocampus peaks during proestrus when ovarian steroids are highest, then declines through the later stages (Woolley et al., 1990). Females generally have double the spine density of males, yet when they are ovariectomized no sex difference is evident, suggesting that the sex difference may be attributable to the activational effects of sex steroids (Gould et al., 1990; Shors et al., 2001). Ovariectomized females display a dramatic decline in spine density in the CA1 region of the hippocampus-a deficit which is reversed with estradiol or progesterone treatment in as low as $40 \mathrm{~min}$ (Gould et al., 1990; MacLusky et al., 2005). These changes in spine density appear to have functional implications, such that ovariectomized mice treated with low-dose estradiol demonstrate both improved learning and increased spine density in the CA1 region (Phan et al., 2012).

Sex differences in spine density are not limited to the hippocampus. For instance, female rats have more large spines in the nucleus accumbens than males (Forlano and Woolley, 2010). Sex differences in spine density have also been noted in the BLA, but somewhat surprisingly, testosterone, and not estradiol alone, appears to mediate these effects (Bender et al., 2017). The aromatase enzyme cytochrome P450 (AROM), present throughout the male and female BLA, is capable of converting testosterone to estradiol (Zhao et al., 2007). Administration of letrozole, an AROM inhibitor, to the BLA results in decreased spine density and eliminates long term potentiation (LTP) in females but not males (Bender et al., 2017). Females have greater excitatory synaptic input in the BLA compared to males, specifically in neurons located in the lateral and basal nuclei. The predominance of each nuclei shifts across the estrous cycle driving the balance of excitation-inhibition which is reflected through changes in BLA-dependent emotional memory across the estrous cycle (Blume et al., 2017). Collectively, these findings highlight the significant impact of sex steroids on the regulation of physiology and spine density in females; however, the following section discusses the impact of sex steroids on spine density that is also evident in males.

\section{Males}

Although males do not produce estrogen or progesterone in as robust of concentrations as females, both sex steroids are present in males. The main source of estrogen in males is the conversion of testosterone to estrogen via aromatase. Gonadectomy in males reduces spine density in the CA1 region of the hippocampus, and this effect can be reversed through treatment with either testosterone or dihydrotestosterone (DHT). Based on the influence of estradiol demonstrated in females, one may hypothesize that estradiol would be 


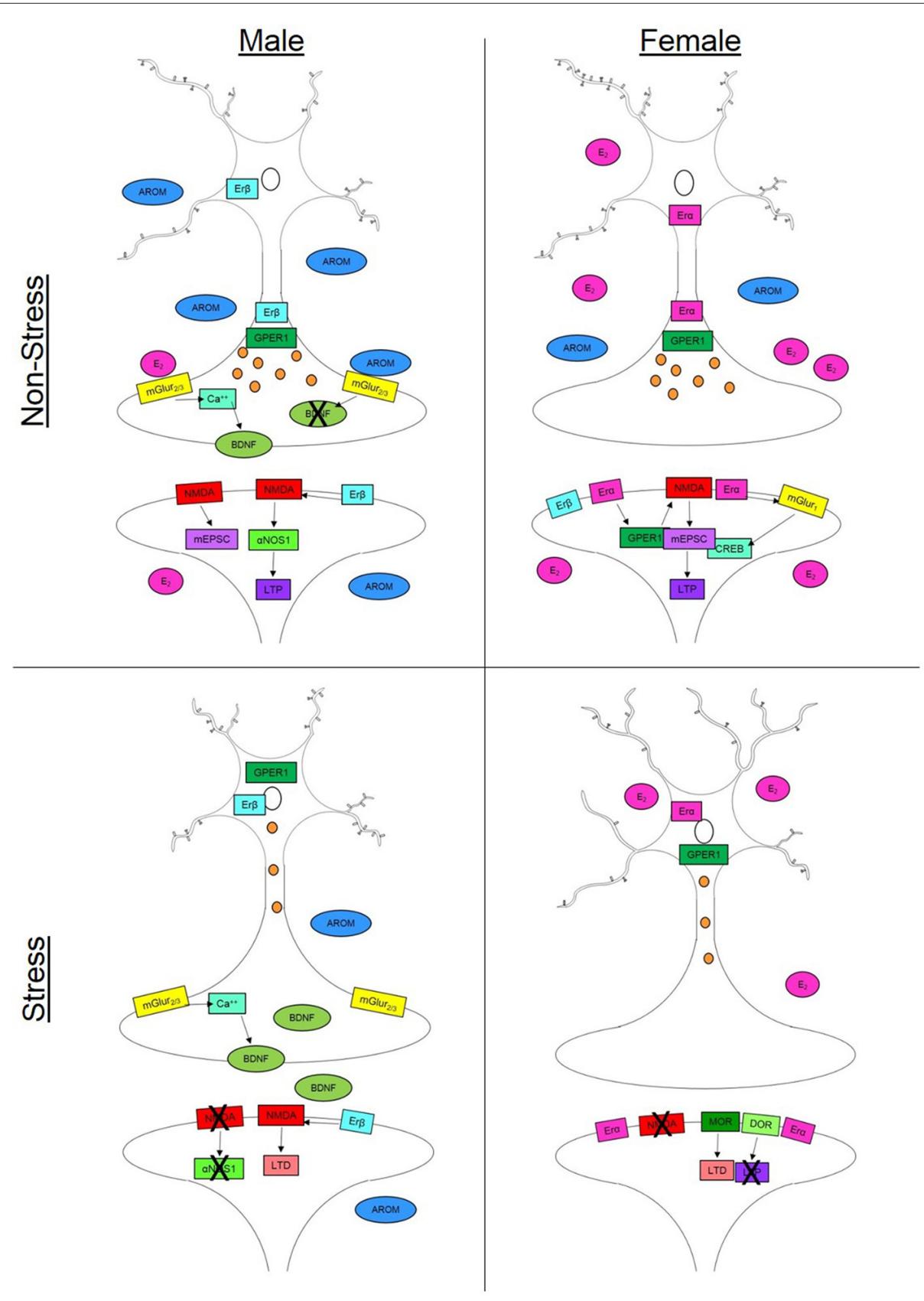

FIGURE 1 | Synaptic plasticity is driven by a variety of sex-specific signaling mechanisms in males and females that can vary throughout the brain. In non-stress conditions, females (top right) have increased spine density compared to males in the hippocampus (top left) but decreased dendritic length in the prefrontal cortex (PFC). This increase in spine density in the female hippocampus can occur via multiple estradiol $\left(E_{2}\right)$-dependent signaling mechanisms. Binding with estrogen receptor alpha (Er $\alpha$ ) or the G-protein coupled estrogen receptor (GPER) can initiate N-methyl-D-aspartate (NMDA) channel signaling increasing mini excitatory postsynaptic currents (mEPCS) which ultimately drive long term potentiation (LTP). Estradiol can also act through Era on metabotropic glutamate receptor 1 (mGluR1) which in turn drives cAMP response element-binding protein (CREB) phosphorylation in females. In males, NMDA activity is driven by activation of estrogen receptor beta (Er $\beta$ ). This signaling cascade includes $\alpha$ nitric oxide synthase-1 ( $\alpha$ NOS1) which drives LTP in males but not females. In the male presynaptic neuron, $E_{2}$-dependent activation of $\mathrm{mGluR}_{2 / 3}$ initiates a calcium $\left(\mathrm{Ca}^{++}\right)$signaling cascade which facilitates the release of brain derived neurotrophic factor (BDNF). Testosterone (AROM) can alter the release of BDNF and other aspects of synaptic plasticity in the baso lateral amygdala. In stress conditions, males (bottom left) show decreased dendritic branching in the PFC but slight increases in spine density in the hippocampus. Possibly accounting for this increase is the reduction in circulating steroid hormones which can allow for increased BDNF release in males. Females (bottom right) on the other hand, experience increased dendritic length in the PFC and hippocampus as well as a suppression of spine growth in the hippocampus following stress. Females exhibit changes in opiate receptor (OR) signaling that can drive long term depression (LTD)-specifically through mu- and delta-OR activity. In the presynaptic neuron, axonal labeling of Era and GPER1 facilitates vesicle transmission down the axon in both males and females. However, in stress conditions (bottom panels), both receptors migrate to the nucleus thereby reducing vesicle trafficking. 
equally efficacious in males; however, direct administration of estradiol is not sufficient to restore spine density in gonadectomized males (Leranth et al., 2003). Furthermore, testosterone appears to inhibit LTP and dendritic sprouting in the male hippocampus. Gonadectomy results in increased LTP and dendritic sprouting in CA3 mossy fibers which is dependent on increased brain derived neurotrophic factor (BDNF) signaling through the tyrosine kinase $\mathrm{B}(\mathrm{TrKB})$ receptor (Skucas et al., 2013). BDNF plays a well-known role in synaptic plasticity ( $\mathrm{Lu}$ et al., 2014) and deficits in BDNF signaling in response to stress can be sex-dependent (Yamaura et al., 2013). Treatment with testosterone eliminated both the castrationinduced increase in LTP and dendritic sprouting, suggesting that testosterone can act to inhibit BDNF-dependent structural plasticity (Skucas et al., 2013). Taken together, these data suggest that estradiol and testosterone regulate spine density in a sex- and region- dependent manner and that BDNF is a likely target mechanism for these hormones to modify synaptic connections.

\section{Sex Differences in Structural Response to Stress}

Dendritic arborization and spine density are both modified by stress and are altered in individuals living with mood disorders. Males overall have more dendritic material than females (Juraska et al., 1985); however, females appear to have more dramatic shifts in dendritic architecture following mildly stressful experiences. For instance, females show increased dendritic length in the dentate gyrus (DG) following the mild stressor of exposure to a novel environment compared to males (Juraska et al., 1985). Interestingly, chronic stress will increase the length and complexity of dendritic arbors in females, possibly making them vulnerable to over-excitation (Farrell et al., 2015), but results in a reduction in dendritic arbors in males in the PFC. The increase is estradiol-dependent as ovariectomized female rats do not demonstrate the stressinduced increase in arborization (Garrett and Wellman, 2009). Chronic stress can also differentially drive subregion-specific plasticity. The dorsal hippocampus demonstrates enhanced markers of plasticity, specifically increased neuropeptide $\mathrm{Y}$ and $\triangle F O S B$ while the ventral region shows a decline in these same markers following chronic unpredictable stress (Hawley and Leasure, 2012). Further complicating our ability to understand sex differences in dendritic responses to stress, is the observation that the type of stressor impacts the outcome. Unlike chronic stress, acute foot shock generates the opposite effect on spine density in the hippocampus. Following acute foot shock, males have increased spine density in area CA1 of the hippocampus while females in diestrus demonstrate a reduction in dendritic spine density (Shors et al., 2001). Interestingly, regardless of the directionality, both males and females show no changes in spine density in response to acute stress if N-methyl-Daspartate (NMDA) receptors are antagonized (Shors et al., 2004), suggesting a potentially unifying mechanism for the disparate consequence of stress. It is evident in female hippocampal slices that estradiol-induced LTP is dependent on an increase in the ratio of NMDA transmission to AMPA transmission (Smith and McMahon, 2005). Female rats that underwent inescapable shock to induce learned helplessness can be protected against the stress-induced loss of spines and LTP if treated with estradiol (Bredemann and McMahon, 2014). Thus, function of the hormone-dependent modifications of the NMDA receptor can dramatically alter the outcome of synaptic plasticity following stress.

\section{SEX DIFFERENCES IN MECHANISMS OF SYNAPTIC PLASTICITY}

\section{Estrogen Receptors}

While changes in spine density and dendritic arborization are evident with cyclic fluctuations of hormones, the mechanisms that drive this structural plasticity are often at the molecular level. As estrogen has a significant impact on structural plasticity, much attention has been given to the mechanisms by which estradiol can modify neuron structure. Estrogens bind with estrogen receptor (Er) $\alpha, \operatorname{Er} \beta$ and G-protein coupled estrogen receptor 1 (GPER1). These receptors are localized throughout the brain of males and females providing estradiol a site of action to modify neuronal structure (Weiland et al., 1997). GPER1 is located throughout hippocampal neurons along the axon, dendritic tree, spine shafts, and is associated with vesicles in the terminal endings. Although anatomical distribution of GPER1 is similar between males and females, increased circulating estrogen concentrations in females leads to elevated axonal labeling of GPER1 in females as compared to males, suggesting alterations in vesicle transport with increased estradiol levels (Waters et al., 2015).

Unlike GPER1, ER $\alpha$ and ER $\beta$ exhibit more notable differences based on sex. Extranuclear ER $\alpha$ distribution in CA1 and CA3 at the ultrastructure level is primarily localized to the dendritic spine heads and at the base of spine shafts. Conversely, $\operatorname{ER} \beta$ is localized to the soma and dendrite membranes (Mitterling et al., 2010). Regardless of circulating estrogen concentrations, females have higher densities of ER $\alpha$ than males (Shughrue et al., 1997; Mitterling et al., 2010), but ER $\alpha$ immunoreactivity within females is sensitive to sex steroids concentrations. During diestrus, when circulating estrogen is at a comparatively low concentration, females demonstrate more $\mathrm{ER} \alpha$-immunoreactivity (ir) and ER $\beta$-ir than that observed in proestrus females (Milner et al., 2001; Mitterling et al., 2010). Overall, elevated circulating concentrations of estradiol pair with reduced extranuclear-ir profiles of $\mathrm{ER} \alpha$ and $\mathrm{ER} \beta$ as compared to periods of low estrogen concentrations which are concomitant with elevations in extranuclear-ir (Mitterling et al., 2010). The shifting patterns of Er localization briefly summarized here, suggest a potential mechanism by which neuron structure could be differentially modified across the estrous cycle and lead to hormone-dependent plasticity in females.

While much of the benefits of estradiol are conferred to females, males also experience increased synaptic plasticity with estradiol signaling. Estradiol can drive potentiation of glutamatergic synapses in males as well as females 
(Teyler et al., 1980; Wong and Moss, 1992). However, the mechanisms by which the potentiation is initiated are sexdependent. Estradiol elicits higher amplitude miniature postsynaptic excitatory currents (mEPSCs) in a synapse specific manner (Oberlander and Woolley, 2016). However, while similar results are evident in males, use of ER-selective agonists has identified a sex-dependent mechanism. In males, the potentiation is driven by $\operatorname{ER} \beta$ while in females it is driven by GPER1. On the other hand, presynaptic potentiation is initiated by $\mathrm{ER} \alpha$ in males but ER $\beta$ in females (Oberlander and Woolley, 2016).

Estradiol's ability to alter function through Er $\alpha$ and $\operatorname{Er} \beta$ (Walf and Frye, 2005; Boulware et al., 2013) is partially dependent on activation of metabotropic glutamate receptor 1a (mGluR1a; Boulware et al., 2013). The differing effects of $\operatorname{Er} \alpha$ and $\operatorname{Er} \beta$ are a result of receptor differences- specifically, differing N-terminal regions (Tremblay et al., 1997). This discrepancy results in activation of separate metabotropic glutamate receptors. Signaling through Er $\alpha$ activates mGluR1 which in turn drives cAMP response element-binding protein (CREB) phosphorylation. Er $\beta$ activation triggers mGluR2/3 signaling resulting in a downregulation of calcium mediated CREB phosphorylation (Boulware et al., 2005). It is also possible that $\operatorname{Er} \beta$ activation may result in disinhibition of BDNF-releasing neurons (Blurton-Jones and Tuszynski, 2002) allowing for increased BDNF signaling to drive synaptic plasticity. As $\operatorname{Er} \beta$ and BDNF are more prevalent in male synaptic plasticity, while Ero appears to drive female-specific plasticity, this may be a primary pathway for sex-dependent synaptic plasticity, allowing for rapid, non-genomic effects of estradiol on hippocampal plasticity (for review see Walf and Frye, 2006). Overall, these data show sex-specific mechanisms by which estradiol interacts with $\operatorname{ER} \alpha$ and $\operatorname{ER} \beta$ to mediate synaptic plasticity.

\section{NMDA Receptor Signaling}

In addition to direct action through its own receptors, estradiol can modify NMDA receptor signaling to drive sex-specific plasticity. In female rats, estrogen-dependent increases in spine density are NMDA-dependent (Woolley and Mcewen, 1994). In gonadectomized females, estradiol benzoate treatment increases NMDA binding in area CA1 of the hippocampus compared to males. However, in males, baseline NMDAr binding is elevated in the DG compared to females (Romeo et al., 2005a). These findings suggest that estradiol's interaction with NMDA receptors is dependent on the organizational effects of steroid signaling. DHT treatment to the hippocampus will increase NMDAr binding density in castrated male rats (Romeo et al., 2005b). Both testosterone and DHT have been shown to increase spinogenesis in males (Kovacs et al., 2003; Leranth et al., 2004) suggesting that activation of NMDA receptors by testosterone or its metabolites is necessary for spinogenesis in males while the same is true for estrogen in females. Furthermore, these sex-dependent mechanism may be exacerbated via cholinergic signaling as estradiol acts on NMDA receptors via cholinergic mechanisms in females but not in males (Volosin et al., 2006). Thus, NMDA receptor signaling is a necessary step for synaptic plasticity in both males and females, especially in response to stress (Shors et al., 2004), however the binding affinity and downstream effects are sexually dimorphic further complicating the interpretation of NMDA-dependent effects on synaptic plasticity.

\section{Nitric Oxide}

Like its relationship with NMDA receptors, estrogen can act on synaptic plasticity indirectly through nitric oxide in a sex-dependent manner. LTP in males is dependent on $\alpha$ nitric oxide synthase-1 ( $\alpha$ NOS1) signaling, however, in females LTP appears not affected in $\alpha$ NOS1 knockouts (Dachtler et al., 2012). This significant sex difference is likely due to the lack of NO and reduced NOS1 expression in the female hippocampus at baseline (Dachtler et al., 2012). However, estradiol application to female mouse derived tissue increases expression of NO in the female brain. Furthermore, NOS levels were altered across the estrous cycle, mirroring fluctuating estradiol levels-specifically, NOS levels were no different from males during proestrus and were lowest during diestrus (Hu et al., 2012). Thus, it is possible that NO-dependent LTP in females may be more likely during proestrous when estradiol is high and availability of $\mathrm{NO}$ is increased. However, it seems likely that NO-dependent LTP is a secondary mechanism by which LTP can be initiated in females, yet in males it is far more prominent.

\section{Opioid Receptors}

Other mechanisms exist beyond steroid hormone-dependent plasticity, to drive changes in synaptic integrity. In proestrus, female rats have higher mossy fiber transmission in cultured hippocampal CA3 cells following administration of the generic opioid receptor antagonist naloxone. Cultured male tissue, on the other hand, does not show altered signaling. These data implicate the opioid receptor as an inhibitor in hippocampal transmission during peak estradiol levels in females. The $\mathrm{m} \mu$-opioid receptor antagonist Cys2, Tyr3, Orn5, Pen7-amide (CTOP) similarly enhances neural transmission, suggesting the $\mathrm{m} \mu$-opioid receptor is specifically down-regulating neural firing in females. Females also exhibit low frequency LTP during proestrus, suggesting that activity threshold is reduced when estradiol is elevated (Harte-Hargrove et al., 2015). Thus, a lowered activity threshold during times of peak estradiol supports enhanced learning and memory in proestrous females (Fernandez et al., 2008; Macbeth and Luine, 2010). However, concomitant inhibition of opioid receptors may be necessary to facilitate this estradiol-dependent benefit. Furthering this conclusion, electron microscopy has revealed more $\delta$-opioid receptor-labeled spines in hippocampal pyramidal cells from proestrous females compared to males. Inhibition of $\delta$-opioid receptors with the antagonist naltrinidole impairs low frequency LTP in proestrous females only. Taken together, these data implicate a sex-specific role of the $\delta$-opioid receptor in LTP signaling in hippocampal pyramidal cells (Harte-Hargrove et al., 2015). As the opiate system can be activated by stress (Chaijale et al., 2013), understanding the role these signaling mechanisms play in plasticity can help define the pathways by which stress can modify synaptic plasticity in a sex-specific manner. 


\section{CONCLUSION}

It is evident that sex differences in synaptic plasticity are driven by both direct and indirect mechanisms of steroid hormones. While these mechanisms exist at the molecular and synaptic levels, they are further reflected in structural differences that ultimately result in sexually-dimorphic behaviors. Recent advances in human neuroimaging have provided insights into the translatability of these sex-differences in synaptic plasticity across mammalian species. Overall changes in white matter, gray matter and cerebral spinal fluid have been observed across the menstrual cycle in human women. Generally, gray and white matter volume appear to increase during the luteal phase when estrogen and progesterone are elevated in women (Catenaccio et al., 2016). Ruigrok et al. (2014) conducted a meta-analysis on gray matter volume and found significant sex-differences with men having more gray matter in the amygdala, hippocampus, parahippocampus, insula, and putamen (Catenaccio et al., 2016). Sex-differences in neural volume are further reflected in a region-specific pattern that fluctuates with the menstrual cycle-similar to what is observed across the rodent estrous cycle. The hippocampus is generally larger in men compared to women, however, during the luteal phase, when estrogen peaks, women see a significant increase in hippocampal volume (Protopopescu et al., 2008). Taken together, these data parallel findings from female rodents that sex-differences evident in certain neural structures are likely dependent on fluctuating hormones in women. Further research is needed to fully elucidate

\section{REFERENCES}

Aggen, S. H., Kendler, K. S., Kubarych, T. S., and Neale, M. C. (2011). Differential age and sex effects in the assessment of major depression: a population-based twin item analysis of the DSM criteria. Twin Res. Hum. Genet. 14, 524-538. doi: $10.1375 /$ twin. 14.6 .524

Allen, L. S., Hines, M., Shryne, J. E., and Gorski, R. A. (1989). Two sexually dimorphic cell groups in the human brain. J. Neurosci. 9, 497-506. doi: 10.1523/JNEUROSCI.09-02-00497.1989

Balthazart, J., Taziaux, M., Holloway, K., Ball, G. F., and Cornil, C. A. (2009). Behavioral effects of brain-derived estrogens in birds. Ann. N Y Acad. Sci. 1163, 31-48. doi: 10.1111/j.1749-6632.2008.03637.x

Bangasser, D. A., and Valentino, R. J. (2014). Sex differences in stress-related psychiatric disorders: neurobiological perspectives. Front. Neuroendocrinol. 35, 303-319. doi: 10.1016/j.yfrne.2014.03.008

Bekhbat, M., and Neigh, G. N. (2018). Sex differences in the neuro-immune consequences of stress: focus on depression and anxiety. Brain Behav. Immun. 67, 1-12. doi: 10.1016/j.bbi.2017.02.006

Bender, R. A., Zhou, L., Vierk, R., Brandt, N., Keller, A., Gee, C. E., et al. (2017). Sex-dependent regulation of aromatase-mediated synaptic plasticity in the basolateral amygdala. J. Neurosci. 37, 1532-1545. doi: 10.1523/JNEUROSCI. 1532-16.2016

Blume, S. R., Freedberg, M., Vantrease, J. E., Chan, R., Padival, M., Record, M. J., et al. (2017). Systems/Circuits sex-and estrus-dependent differences in rat basolateral amygdala. J. Neurosci. 37, 10567-10586. doi: 10.1523/JNEUROSCI. 0758-17.2017

Blurton-Jones, M., and Tuszynski, M. H. (2002). Estrogen receptor- $\beta$ colocalizes extensively with parvalbumin-labeled inhibitory neurons in the cortex, amygdala, basal forebrain, and hippocampal formation of intact and ovariectomized adult rats. J. Comp. Neurol. 452, 276-287. doi: 10.1002/cne. 10393

Boulware, M. I., Heisler, J. D., and Frick, K. M. (2013). The memoryenhancing effects of hippocampal estrogen receptor activation involve sex-differences in human neuroplasticity, however, it is clear that sex-differences are conserved across mammalian species. By understanding the synaptic mechanisms underlying behavioral differences between males and females, we can derive more information on the source of functional changes as well as their possible dysfunction when, and if, it occurs. Incorporating both males and females into these studies is essential given the extensive sex-differences in synaptic plasticity mechanisms and their functional outcomes.

\section{AUTHOR CONTRIBUTIONS}

$\mathrm{MH}$ outlined, researched and wrote this review article. In addition, she composed the figure. LP provided editorial comments and suggestions on the research areas to include. GN assisted in the drafting and editing of this manuscript and advised $\mathrm{MH}$, a postdoctoral trainee, during the process.

\section{FUNDING}

GN received support from the Office of Extramural Research, National Institutes of Health (grant nos. R01MH110364 and NR014886). LP received support from the Office of Extramural Research, National Institutes of Health (grant no. NS044372 and NS056247). MH is a postdoctoral fellow supported by the Office of Extramural Research, National Institutes of Health (grant no. K12GM093857).

metabotropic glutamate receptor signaling. J. Neurosci. 33, 15184-15194 doi: 10.1523/JNEUROSCI.1716-13.2013

Boulware, M. I., Weick, J. P., Becklund, B. R., Kuo, S. P., Groth, R. D., and Mermelstein, P. G. (2005). Estradiol activates group I and II metabotropic glutamate receptor signaling, leading to opposing influences on cAMP response element-binding protein. J. Neurosci. 25, 5066-5078. doi: 10.1523/JNEUROSCI.1427-05.2005

Bredemann, T. M., and McMahon, L. L. (2014). $17 \beta$ estradiol increases resilience and improves hippocampal synaptic function in helpless ovariectomized rats. Psychoneuroendocrinology 42, 77-88. doi: 10.1016/j.psyneuen.2014.01.004

Butcher, R. L., Collins, W. E., and Fugo, N. W. (1974). Plasma concentration of LH, FSH, prolactin, progesterone and estradiol-17/3 throughout the 4-day estrous cycle of the rat. Endocrinology 94, 1704-1708. doi: 10.1210/endo-94-6-1704

Campi, K. L., Jameson, C. E., and Trainor, B. C. (2013). Sexual dimorphism in the brain of the monogamous california mouse (Peromyscus californicus). Brain Behav. Evol. 81, 236-249. doi: 10.1159/000353260

Catenaccio, E., Mu, W., and Lipton, M. L. (2016). Estrogen- and progesteronemediated structural neuroplasticity in women: evidence from neuroimaging. Brain Struct. Funct. 221, 3845-3867. doi: 10.1007/s00429-016-1197-x

Chaijale, N. N., Curtis, A. L., Wood, S. K., Zhang, X.-Y., Bhatnagar, S., Reyes, B. A., et al. (2013). Social stress engages opioid regulation of locus coeruleus norepinephrine neurons and induces a state of cellular and physical opiate dependence. Neuropsychopharmacology 38, 1833-1843. doi: 10.1038/npp. 2013.117

Dachtler, J., Hardingham, N. R., and Fox, K. (2012). The role of nitric oxide synthase in cortical plasticity is sex specific. J. Neurosci. 32, 14994-14999. doi: 10.1523/JNEUROSCI.3189-12.2012

Farrell, M. R., Gruene, T. M., and Shansky, R. M. (2015). The influence of stress and gonadal hormones on neuronal structure and function. Horm. Behav. 76, 118-124. doi: 10.1016/j.yhbeh.2015.03.003

Fernandez, S. M., Lewis, M. C., Pechenino, A. S., Harburger, L. L., Orr, P. T., Gresack, J. E., et al. (2008). Estradiol-induced enhancement of object memory consolidation involves hippocampal extracellular signal-regulated 
kinase activation and membrane-bound estrogen receptors. J. Neurosci. 28, 8660-8667. doi: 10.1523/JNEUROSCI.1968-08.2008

Forlano, P., and Woolley, C. (2010). Quantitative analysis of pre- and postsynaptic sex differences in the nucleus accumbens. J. Comp. Neurol. 518, 1330-1348. doi: $10.1002 /$ cne.22279

Galea, L. A., McEwen, B. S., Tanapat, P., Deak, T., Spencer, R. L., and Dhabhar, F. S. (1997). Sex differences in dendritic atrophy of CA3 pyramidal neurons in response to chronic restraint stress. Neuroscience 81, 689-697. doi: 10.1016/s0306-4522(97)00233-9

Galea, L. A. M., Spritzer, M. D., Barker, J. M., and Pawluski, J. L. (2006). Gonadal hormone modulation of hippocampal neurogenesis in the adult. Hippocampus 16, 225-232. doi: 10.1002/hipo.20154

Garrett, J. E., and Wellman, C. L. (2009). Chronic stress effects on dendritic morphology in medial prefrontal cortex: sex differences and estrogen dependence. Neuroscience 162, 195-207. doi: 10.1016/j.neuroscience.2009. 04.057

Gobinath, A. R., Mahmoud, R., and Galea, L. A. M. (2015). Influence of sex and stress exposure across the lifespan on endophenotypes of depression: focus on behavior, glucocorticoids, and hippocampus. Front. Neurosci. 8:420. doi: $10.3389 /$ fnins.2014.00420

Gorski, R. A., Gordon, J. H., Shryne, J. E., and Southam, A. M. (1978). Evidence for a morphological sex difference within the medial preoptic area of the rat brain. Brain Res. 148, 333-346. doi: 10.1016/0006-8993(78)90723-0

Gould, E., Woolley, S., Frankfurt, M., and McEwen, B. S. (1990). Gonadal steroids regulate dendritic spine density in hippocampal pyramidal cells in adulthood. J. Neurosci. 10, 1286-1291. doi: 10.1523/JNEUROSCI.10-04-01286.1990

Harte-Hargrove, L. C., Varga-Wesson, A., Duffy, A. M., Milner, T. A., and Scharfman, H. E. (2015). Opioid receptor-dependent sex differences in synaptic plasticity in the hippocampal mossy fiber pathway of the adult rat. J. Neurosci. 35, 1723-1738. doi: 10.1523/JNEUROSCI.0820-14.2015

Hawley, D. F., and Leasure, J. L. (2012). Region-specific response of the hippocampus to chronic unpredictable stress. Hippocampus 22, 1338-1349. doi: 10.1002/hipo.20970

Holtmaat, A., and Svoboda, K. (2009). Experience-dependent structural synaptic plasticity in the mammalian brain. Nat. Rev. Neurosci. 10, 647-658. doi: $10.1038 / \mathrm{nrn} 2699$

Hu, Y., Wu, D.-L., Luo, C.-X., Zhu, L.-J., Zhang, J., Wu, H.-Y., et al. (2012). Hippocampal nitric oxide contributes to sex difference in affective behaviors. Proc. Natl. Acad. Sci. U S A 109, 14224-14229. doi: 10.1073/pnas.1207461109

Hyer, M. M., Khantsis, S., Venezia, A. C., Madison, F. N., Hallgarth, L., Adekola, E., et al. (2017). Estrogen-dependent modifications to hippocampal plasticity in paternal California mice (Peromyscus californicus). Horm. Behav. 96, 147-155. doi: 10.1016/j.yhbeh.2017.09.015

Ingalhalikar, M., Smith, A., Parker, D., Satterthwaite, T. D., Elliott, M. A., Ruparel, K., et al. (2014). Sex differences in the structural connectome of the human brain. Proc. Natl. Acad. Sci. U S A 111, 823-828. doi: 10.1073/pnas. 1316909110

Juraska, J. M., Fitch, J. M., Henderson, C., and Rivers, N. (1985). Sex differences in the dendritic branching of dentate granule cells following differential experience. Brain Res. 333, 73-80. doi: 10.1016/0006-8993(85)90125-8

Kempermann, G., Song, H., and Gage, F. H. (2015). Neurogenesis in the adult hippocampus. Cold Spring Harb. Perspect. Biol. 7:a018812. doi: 10.1101/cshperspect.a018812

Kovacs, E. G., MacLusky, N. J., and Leranth, A. C. (2003). Effects of testosterone on hippocampal CA1 spine synaptic density in the male rat are inhibited by fimbria/fornix transection. Neuroscience 122, 807-810. doi: 10.1016/j. neuroscience.2003.08.046

Leranth, C., Hajszan, T., and MacLusky, N. J. (2004). Androgens increase spine synapse density in the CA1 hippocampal subfield of ovariectomized female rats. J. Neurosci. 24, 495-499. doi: 10.1523/JNEUROSCI.4516-03.2004

Leranth, C., Petnehazy, O., and MacLusky, N. J. (2003). Gonadal hormones affect spine synaptic density in the CA1 hippocampal subfield of male rats. J. Neurosci. 23, 1588-1592. doi: 10.1523/JNEUROSCI.23-05-01588.2003

Leuner, B., and Shors, T. J. (2013). Stress, anxiety, and dendritic spines: what are the connections? Neuroscience 251, 108-119. doi: 10.1016/j.neuroscience.2012. 04.021

Livneh, Y., and Mizrahi, A. (2012). Experience-dependent plasticity of mature adult-born neurons. Nat. Neurosci. 15, 26-28. doi: 10.1038/nn.2980
Lu, B., Nagappan, G., and Lu, Y. (2014). "BDNF and synaptic plasticity, cognitive function, and dysfunction," in Neurotrophic Factors, eds G. R. Lewin and B. D. Carter (Berlin, Heidelberg: Springer), 223-250.

Macbeth, A. H., and Luine, V. N. (2010). Changes in anxiety and cognition due to reproductive experience: a review of data from rodent and human mothers. Neurosci. Biobehav. Rev. 34, 452-467. doi: 10.1016/j.neubiorev.2009. 08.011

MacLusky, N. J., Luine, V. N., Hajszan, T., and Leranth, C. (2005). The $17 \alpha$ and $17 \beta$ isomers of estradiol both induce rapid spine synapse formation in the CA1 hippocampal subfield of ovariectomized female rats. Endocrinology 146, 287-293. doi: 10.1210/en.2004-0730

Mak, G. K., and Weiss, S. (2010). Paternal recognition of adult offspring mediated by newly generated CNS neurons. Nat. Neurosci. 13, 753-758. doi: 10.1038/nn. 2550

McEwen, B. S. (2010). Stress, sex, and neural adaptation to a changing environment: mechanisms of neuronal remodeling. Ann. N Y Acad. Sci. 1204, E38-E59. doi: 10.1111/j.1749-6632.2010.05568.x

Milner, T. A., McEwen, B. S., Hayashi, S., Li, C. J., Alves, L. P., and Reagan, S. E. (2001). Ultrastructural evidence that hippocampal $\alpha$ estrogen receptors are located at extranuclear sites. J. Comp. Neurol. 429, 355-371. doi: 10.1002/10969861(20010115)429:3<355::aid-cne1>3.3.co;2-r

Mitterling, K. L., Spencer, J. L., Dziedzic, N., Shenoy, S., McCarthy, K., Waters, E. M., et al. (2010). Cellular and subcellular localization of estrogen and progestin receptor immunoreactivities in the mouse hippocampus. J. Comp. Neurol. 518, 2729-2743. doi: 10.1002/cne.22361

Naninck, E. F. G., Lucassen, P. J., and Bakker, J. (2011). Sex differences in adolescent depression: do sex hormones determine vulnerability? J. Neuroendocrinol. 23, 383-392. doi: 10.1111/j.1365-2826.2011.02125.x

Nottebohm, F., and Arnold, A. (1976). Sexual dimorphism in vocal control areas of the songbird brain. Science 194, 211-213. doi: 10.1126/science.959852

Oberlander, J. G., and Woolley, C. S. (2016). 17ß-Estradiol acutely potentiates glutamatergic synaptic transmission in the hippocampus through distinct mechanisms in males and females. J. Neurosci. 36, 3677-3690. doi: 10.1523/JNEUROSCI.4437-15.2016.

Ormerod, B. K., Lee, T. T. Y., and Galea, L. A. M. (2004). Estradiol enhances neurogenesis in the dentate gyri of adult male meadow voles by increasing the survival of young granule neurons. Neuroscience 128, 645-654. doi: 10.1016/j. neuroscience.2004.06.039

Parducz, A., Hajszan, T., MacLusky, N. J., Hoyk, Z., Csakvari, E., Kurunczi, A., et al. (2006). Synaptic remodeling induced by gonadal hormones: neuronal plasticity as a mediator of neuroendocrine and behavioral responses to steroids. Neuroscience 138, 977-985. doi: 10.1016/j.neuroscience.2005.07.008

Phan, A., Gabor, C. S., Favaro, K. J., Kaschack, S., Armstrong, J. N., MacLusky, N. J., et al. (2012). Low doses of 17ß-estradiol rapidly improve learning and increase hippocampal dendritic spines. Neuropsychopharmacology 37, 2299-2309. doi: 10.1038/npp.2012.82

Piccinelli, M., and Wilkinson, G. (2000). Gender differences in depression. Critical review. Br. J. Psychiatry 177, 486-492. doi: 10.1192/bjp.177.6.486

Protopopescu, X., Butler, T., Pan, H., Root, J., Altemus, M., Polanecsky, M., et al. (2008). Hippocampal structural changes across the menstrual cycle. Hippocampus 18, 985-988. doi: 10.1002/hipo.20468

Qiao, H., Li, M., Xu, C., Chen, H., An, S., and Ma, X. (2016). Dendritic spines in depression: what we learned from animal models. Neural Plast. 2016:8056370. doi: 10.1155/2016/8056370

Romeo, R. D., McCarthy, J. B., Wang, A., Milner, T. A., and McEwen, B. S. (2005a). Sex differences in hippocampal estradiol-induced n-methyl-dspartic acid binding and ultrastructural localization of estrogen receptor- $\alpha$. Neuroendocrinology 81, 391-399. doi: 10.1159/000089557

Romeo, R. D., Staub, D., Jasnow, A. M., Karatsoreos, I. N., Thornton, J. E., and McEwen, B. S. (2005b). Dihydrotestosterone increases hippocampal Nmethyl-D-aspartate binding but does not affect choline acetyltransferase cell number in the forebrain or choline transporter levels in the CA1 region of adult male rats. Endocrinology 146, 2091-2097. doi: 10.1210/en.20 04-0886

Ruble, D. N., Greulich, F., Pomerantz, E. M., and Gochberg, B. (1993). The role of gender-related processes in the development of sex differences in self-evaluation and depression. J. Affect. Disord. 29, 97-128. doi: 10.1016/01650327(93)90027-h 
Ruigrok, A. N. V., Salimi-Khorshidi, G., Lai, M.-C., Baron-Cohen, S., Lombardo, M. V., Tait, R. J., et al. (2014). A meta-analysis of sex differences in human brain structure. Neurosci. Biobehav. Rev. 39, 34-50. doi: 10.1016/j. neubiorev.2013.12.004

Shors, T. J., Chua, C., and Falduto, J. (2001). Sex differences and opposite effects of stress on dendritic spine density in the male versus female hippocampus. J. Neurosci. 21, 6292-6297. doi: 10.1523/JNEUROSCI.21-16-06292.2001

Shors, T. J., Falduto, J., and Leuner, B. (2004). The opposite effects of stress on dendritic spines in male vs. female rats are NMDA receptor-dependent. Eur. J. Neurosci. 19, 145-150. doi: 10.1046/j.1460-9568.2003.03065.x

Shughrue, P. J., Lane, M. V., and Merchenthaler, I. (1997). Comparative distribution of estrogen receptor- $\alpha$ and $-\beta$ mRNA in the rat central nervous system. J. Comp. Neurol. 388, 507-525. doi: 10.1002/(sici)10969861(19971201)388:4<507::aid-cne1>3.0.c0;2-6

Skucas, V. A., Duffy, A. M., Harte-Hargrove, L. C., Magagna-Poveda, A., Radman, T., Chakraborty, G., et al. (2013). Testosterone depletion in adult male rats increases mossy fiber transmission, LTP, and sprouting in area CA3 of hippocampus. J. Neurosci. 33, 2338-2355. doi: 10.1523/JNEUROSCI.385712.2013

Smith, C. C., and McMahon, L. L. (2005). Estrogen-induced increase in the magnitude of long-term potentiation occurs only when the ratio of NMDA transmission to AMPA transmission is increased. J. Neurosci. 25, 7780-7791. doi: 10.1523/JNEUROSCI.0762-05.2005

Swaab, D. F., and Fliers, E. (1985). A sexually dimorphic nucleus in the human brain. Science 228, 1112-1115. doi: 10.1126/science.3992248

Tanapat, P., Hastings, N. B., and Gould, E. (2005). Ovarian steroids influence cell proliferation in the dentate gyrus of the adult female rat in a dose- and time-dependent manner. J. Comp. Neurol. 481, 252-265. doi: 10.1002/cne. 20385

Teyler, T., Vardaris, R., Lewis, D., and Rawitch, A. (1980). Gonadal steroids: effects on excitability of hippocampal pyramidal cells. Science 209, 1017-1018. doi: 10.1126/science.7190730

Tremblay, G. B., Tremblay, A., Copeland, N. G., Gilbert, D. J., Jenkins, N. A., Labrie, F., et al. (1997). Cloning, chromosomal localization, and functional analysis of the murine estrogen receptor $\beta$. Mol. Endocrinol. 11, 353-365. doi: 10.1210/mend.11.3.9902

Vivar, C., Peterson, B. D., and van Praag, H. (2016). Running rewires the neuronal network of adult-born dentate granule cells. Neuroimage 131, 29-41. doi: 10.1016/j.neuroimage.2015.11.031

Volosin, M., Song, W., Almeida, R. D., Kaplan, D. R., Hempstead, B. L., and Friedman, W. J. (2006). Interaction of survival and death dignaling in dasal forebrain neurons: roles of neurotrophins and proneurotrophins. J. Neurosci. 26, 7756-7766. doi: 10.1523/JNEUROSCI.1560-06.2006

Vyas, A., Mitra, R., Shankaranarayana Rao, B. S., and Chattarji, S. (2002). Chronic stress induces contrasting patterns of dendritic remodeling in hippocampal and amygdaloid neurons. J. Neurosci. 22, 6810-6818. doi: 10.1523/JNEUROSCI.2215-06810.2002

Walf, A. A., and Frye, C. A. (2005). ERb-Selective estrogen receptor modulators produce antianxiety behavior when administered systemically to ovariectomized rats. Neuropsychopharmacology 30, 1598-1609. doi: 10.1038/sj. npp. 1300713

Walf, A. A., and Frye, C. A. (2006). A review and update of mechanisms of estrogen in the hippocampus and amygdala for anxiety and depression behavior. Neuropsychopharmacology 31, 1097-1111. doi: 10.1038/sj.npp. 1301067

Waters, E. M., Thompson, L. I., Patel, P., Gonzales, A. D., Ye, H. Z., Filardo, E. J., et al. (2015). G-protein-coupled estrogen receptor 1 is anatomically positioned to modulate synaptic plasticity in the mouse hippocampus. J. Neurosci. 35, 2384-2397. doi: 10.1523/JNEUROSCI.1298-14.2015

Weiland, N. G., Orikasa, C., Hayashi, S., and McEwen, B. S. (1997). Distribution and hormone regulation of estrogen receptor immunoreactive cells in the hippocampus of male and female rats. J. Comp. Neurol. 388, 603-612. doi: 10.1002/(sici)1096-9861(19971201)388:4<603::aid-cne8>3.0. co;2-6

Wong, M., and Moss, R. L. (1992). Long-term and short-term electrophysiological effects of on the synaptic properties of hippocampal CA1 neurons estrogen. J. Neurosci. 12, 3217-3225. doi: 10.1523/JNEUROSCI.12-08-032 17.1992

Woolley, S., Gould, E., Frankfurt, M., and Mcewen, S. (1990). Naturally occurring fluctuation in dendritic spine density on adult hippocampal pyramidal neurons. J. Neurosci. 10, 4035-4039. doi: 10.1523/JNEUROSCI.10-12-04 035.1990

Woolley, C. S., and Mcewen, B. S. (1994). Estradiol regulates hippocampal dendritic spine density via an N-methyl-D-aspartate receptor-dependent mechanism. J. Neurosci. 14, 7680-7687. doi: 10.1523/JNEUROSCI.14-1207680.1994

Yamaura, K., Bi, Y., Ishiwatari, M., Oishi, N., Fukata, H., and Ueno, K. (2013). Sex differences in stress reactivity of hippocampal BDNF in mice are associated with the female preponderance of decreased locomotor activity in response to restraint stress. Zoolog. Sci. 30, 1019-1024. doi: 10.2108/zsj. 30.1019

Zhao, C., Fujinaga, R., Tanaka, M., Yanai, A., Nakahama, K., and Shinoda, K. (2007). Region-specific expression and sex-steroidal regulation on aromatase and its mRNA in the male rat brain: immunohistochemical and in situ hybridization analyses. J. Comp. Neurol. 500, 557-573. doi: 10.1002/cne. 21193

Conflict of Interest Statement: The authors declare that the research was conducted in the absence of any commercial or financial relationships that could be construed as a potential conflict of interest.

Copyright (C) 2018 Hyer, Phillips and Neigh. This is an open-access article distributed under the terms of the Creative Commons Attribution License (CC BY). The use, distribution or reproduction in other forums is permitted, provided the original author(s) and the copyright owner(s) are credited and that the original publication in this journal is cited, in accordance with accepted academic practice. No use, distribution or reproduction is permitted which does not comply with these terms. 